\title{
Differential Diagnosis of Atypical Parathyroid Adenoma and Parathyroid Carcinoma in a Case With Severe Hypercalcemia
}

\author{
Husniye Baser ${ }^{\mathrm{a}, \mathrm{g}}$, Ali Karagoz ${ }^{\mathrm{b}}$, Ahmet Okus $^{\mathrm{c}}$, Mustafa Cayci ${ }^{\mathrm{d}}$, Meryem Ilkay Eren Karanis ${ }^{\mathrm{e}}$, \\ Ferda Sevimli Burnik ${ }^{\mathrm{a}}$, Salih Baser ${ }^{\mathrm{f}}$
}

\begin{abstract}
Atypical parathyroid adenoma is among the tumors diagnosed difficultly and including some histological features of parathyroid carcinoma. In literature, no definite criteria have been considered to be present to distinguish atypical parathyroid adenoma preoperatively from parathyroid carcinoma. A 65-year-old woman was admitted to our clinic with complaints of arthralgia, myalgia, fatigue and loss of appetite. She had severe hypercalcemia (serum calcium $17.2 \mathrm{mg} / \mathrm{dL}$ ) and hypophosphatemia (serum phosphate 1.9 $\mathrm{mg} / \mathrm{dL}$ ) along with an elevated intact parathyroid hormone level of $879 \mathrm{pg} / \mathrm{mL}$. Renal functions were within normal limits. The patient was administered with intravenous hydration and diuretic treatments because of severe hypercalcemia. Six sessions of hemodialysis were performed. In neck ultrasonography, multinodular goitre was detected. Tc- $99 \mathrm{~m}$ sestamibi scintigraphy revealed a focal involvement at the middle-inferior region of left thyroid lobe. Neck magnetic resonance imagination revealed a nodular lesion in size of $22 \times 14 \mathrm{~mm}$ at the posterior region of left thyroid lobe. Parathyroidectomy guided by intraoperative gamma probe was performed. The lesion was histopathologically consistent with atypical parathyroid adenoma. In the postoperative period, serum
\end{abstract}

calcium and intact parathyroid hormone levels were decreased as levels of $7 \mathrm{mg} / \mathrm{dL}$ and $42.6 \mathrm{pg} / \mathrm{mL}$, respectively. We reported an atypical parathyroid adenoma accompanied by severe hypercalcemia and hyperparathyroidism.

Keywords: Severe hypercalcemia; Primary hyperparathyroidism; Atypical parathyroid adenoma; Parathyroid carcinoma

\section{Introduction}

Parathyroid carcinoma (PC) and atypical parathyroid adenoma (APA) are among rarely encountered causes of primary hyperparathyroidism (PHPT). PC constitutes 0.5 to $4 \%$ of all cases of primary hyperparathyroidism [1]. APA includes some histological features of $\mathrm{PC}$ and is difficult to be distinguished from $\mathrm{PC}$, and so the condition may lead to the underor overestimation in the treatment of PC and APA.

$\mathrm{PC}$ progresses slowly and may give rise to higher rate of deaths because of metabolic complications of hypercalcemia [2]. While severe hypercalcemia is considered a risk

${ }^{a}$ Konya Education and Research Hospital, Department of

Endocrinology and Metabolism, Konya, Turkey

${ }^{b}$ Konya Education and Research Hospital, Department of Nephrology,

Konya, Turkey

${ }^{\mathrm{c}}$ Konya Education and Research Hospital, Department of General Surgery, Konya, Turkey

${ }^{\mathrm{d} K o n y a ~ E d u c a t i o n ~ a n d ~ R e s e a r c h ~ H o s p i t a l, ~ D e p a r t m e n t ~ o f ~ N u c l e a r ~}$ Medicine, Konya, Turkey

${ }^{\mathrm{e} K o n y a ~ E d u c a t i o n ~ a n d ~ R e s e a r c h ~ H o s p i t a l, ~ D e p a r t m e n t ~ o f ~ P a t h o l o g y, ~}$ Konya, Turkey

${ }^{\mathrm{f}}$ Konya Education and Research Hospital, Department of Internal Medicine, Konya, Turkey

${ }^{g}$ Corresponding author: Husniye Baser, Konya Education and Research

Hospital, Department of Endocrinology and Metabolism, Meram,

Konya, Turkey. Email: drhusniyebaser@yahoo.com.tr

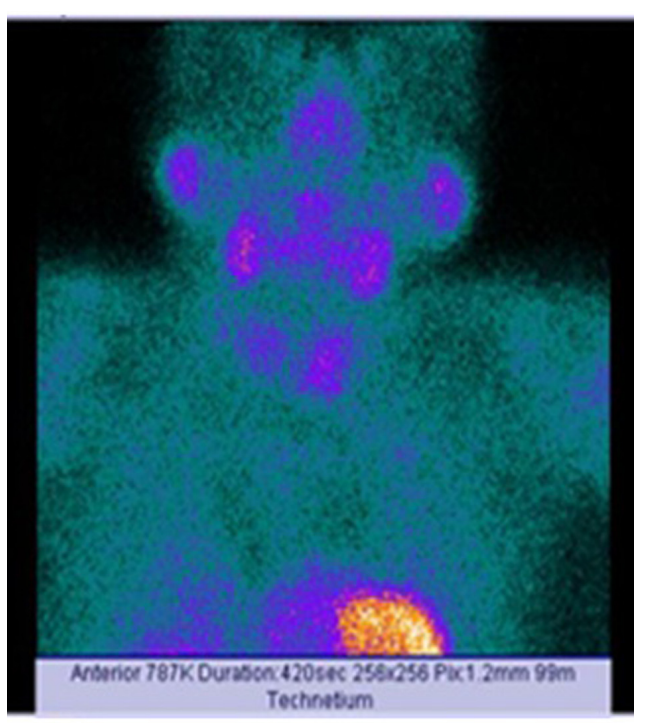

Figure 1. Scanning of the case via Tc-99m sestamibi. 


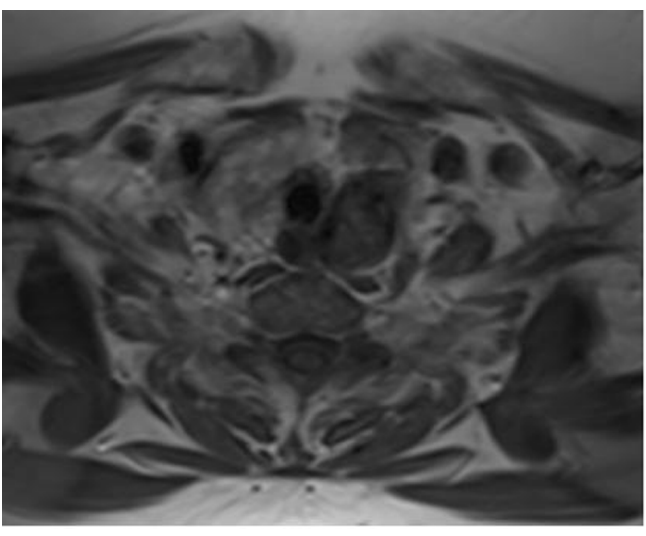

Figure 2. Nodular lesion at the posterior region of left thyroid lobe on neck magnetic resonance imaging.

factor for malignancy, most of the patients with PC virtually display clinical manifestations indistinguishable from those in patients with APA or parathyroid adenoma [3]. In order to distinguish APA from PC, no certain clinical and biochemical criteria are present in preoperative period. Although they are valuable imaging methods to localize the lesion, neck ultrasonography (US) and Tc-99m sestamibi scintigraphy are inadequate techniques to distinguish between benign and malignant lesions. It is also difficult to distinguish APA from PC in intraoperative period, and intraoperative frozensection gives no reliable and substantial clues. The fact that such findings as adherence to surrounding structures, fibrous bands, trabecular growth and mitoses can also be found in benign lesion histologically may lead to confusion in the differential diagnosis of PC $[4,5]$. A definitive diagnosis of malignancy should be restricted to tumors showing the existence of vascular invasion, capsular invasion with growth into adjecent tissues or metastases. A case diagnosed with APA that was accompanied by high levels of calcium (Ca)

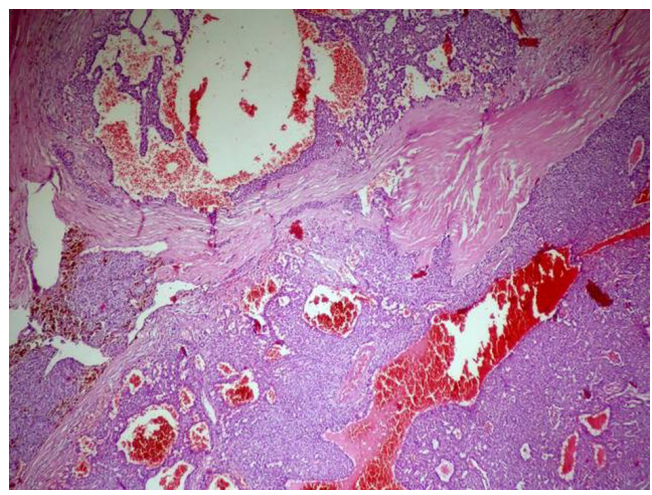

Figure 3. Round to oval shaped proliferative cells seperated by dense fibrotic bands, and cystic and hemorrhagic areas are seen (hematoxyline and eosin stain; original magnification $\times 50)$.

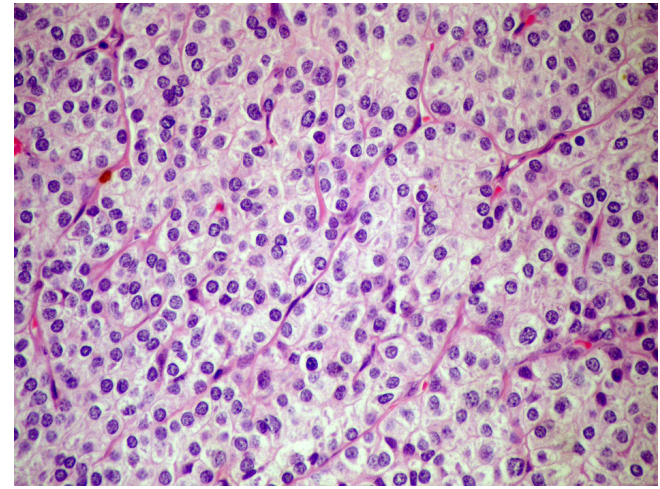

Figure 4. Round to oval shaped parathyroid cell proliferation indicating no marked pleomorphism without mitosis and fat tissue (hematoxyline and eosin stain; original magnification $\times 400)$.

and intact parathyroid hormone (iPTH) was presented.

\section{Case Report}

A 65-year-old woman was admitted to our clinic with arthralgia, myalgia, fatigue and loss of appetite. The case exhibited a history of hypertension, but not nephrolithiasis or pancreatitis. The physical examination showed no abnormal findings, except for a $2.5 \times 2.5 \mathrm{~cm}$ sized mass palpable on left thyroid lobe. Biochemical findings were as follows: serum urea, $47 \mathrm{mg} / \mathrm{dL}$ (reference range: $15-55 \mathrm{mg} / \mathrm{dL}$ ); serum creatinine, $1.1 \mathrm{mg} / \mathrm{dL}$ (reference range: $0.7-1.3 \mathrm{mg} / \mathrm{dL}$ ); serum $\mathrm{Ca}, 17.2 \mathrm{mg} / \mathrm{dL}$ (reference range: $8.8-10.0 \mathrm{mg} / \mathrm{dL}$ ); serum phosphate, $1.9 \mathrm{mg} / \mathrm{dL}$ (reference range: $2.5-4.5 \mathrm{mg}$ / $\mathrm{dL}$ ); serum albumin, $3.4 \mathrm{gr} / \mathrm{dL}$ (reference range: 3.4 - $4.8 \mathrm{gr} /$ $\mathrm{dL}$ ); serum alkaline phosphatase (ALP), $183 \mathrm{U} / \mathrm{L}$ (reference range: 40 - $150 \mathrm{U} / \mathrm{L}$ ); iPTH, $879 \mathrm{pg} / \mathrm{mL}$ (reference range: 11

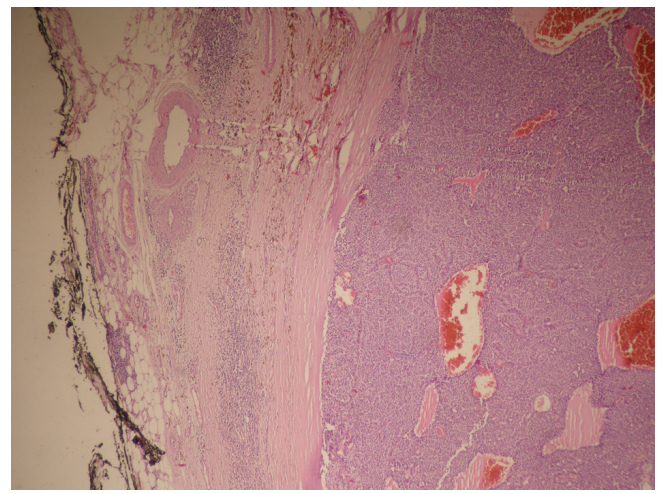

Figure 5. Parathyroid cell proliferation surrounded by thick fibrous capsule without vessel invasion, complete capsule invasion and invasion to the adjacent structures (hematoxyline and eosin stain; original magnification $\times 50$ ). 
- $67 \mathrm{pg} / \mathrm{mL}$ ); and, 24-hour urine Ca excretion, $425 \mathrm{mg} / \mathrm{d}$, and our case was found to be euthyroid.

As a result of the determination of severe hypercalcemia, intravenous hydration and furosemide as diuretic were started, six sessions of hemodialysis were carried out, and the level of serum Ca was decreased to $14.6 \mathrm{mg} / \mathrm{dL}$.

Neck US demonstrated multinodular goitre, but no finding suggesting parathyroid adenoma was detected. Because the diagnosis was clinically and biochemically consistent with primary hyperparathyroidism, parathyroid scintigraphy was performed. Tc-99m sestamibi scintigraphy revealed a suspected focal involvement as to parathyroid adenoma at the middle-inferior region of left thyroid lobe (Fig. 1). Neck magnetic resonance imaging (MRI), performed in order to determine the localization and size of parathyroid adenoma, revealed a regular shaped nodular lesion in size of approximately $22 \times 14 \mathrm{~mm}$ at the posterior region of left thyroid lobe (Fig. 2). US of urinary system showed nephrolithiasis, and on bone X-ray, osteoporotic alterations were observed.

Parathyroidectomy guided by intraoperative gamma probe was performed, and a $3.5 \times 3 \times 2 \mathrm{~cm}$-sized parathyroid adenoma was excised. Histopathologically, well-circumscribed parathyroid cell proliferation with solid growth pattern was seen. Round to oval shaped proliferative cells were surrounded by thick fibrous capsule and seperated by dense fibrotic bands (Fig. 3). Cystic and hemorrhagic areas were also seen. Stromal fat content was absent. No marked pleomorphism and mitotic figure was present (Fig. 4). Ki-67 proliferation index was less than $1 \%$, and no invasions of vessel, complete capsule and to the adjacent structures were observed (Fig. 5). In an area, the invasion of parathyroid cell proliferation into the capsule was observed, but not the complete invasion of the capsule. Positive immunoreaction with cyclin D1 was witnessed. Findings were considered to be related to APA.

On the first postoperative day, serum Ca and iPTH levels were decreased to $11.6 \mathrm{mg} / \mathrm{dL}$ and $42.6 \mathrm{pg} / \mathrm{mL}$, respectively. On the second postoperative day, serum $\mathrm{Ca}$ level was found to be decreased to $7 \mathrm{mg} / \mathrm{dL}$, and oral calcium and vitamin D replacements were commenced. On follow-ups, hypocalcemia was determined to be improved, and so calcium and vitamin $\mathrm{D}$ were discontinued. On the 15th day following the operation, serum $\mathrm{Ca}$ and iPTH levels were detected to be 9.1 $\mathrm{mg} / \mathrm{dL}$ and $212 \mathrm{pg} / \mathrm{mL}$, respectively.

\section{Discussion}

PHPT is a disease due to increased PTH secretion from one or more parathyroid glands [6]. It is seen in $0.1-0.3 \%$ of population, more often in women $(1 / 500)$ than men $(1 / 2,000)$ [7]. While the cause is a single adenoma in parathyroid gland in $75-85 \%$ of cases, both adenomas in more than one gland and PC, rarely, may lead to PHPT [6]. Although various patients with PHPT display parathyroid tumors with some histologic characteristics of PC, the existence of such histologic characteristics is insufficient to diagnose the cases with cancer, and these tumors are usually classified as atypical adenomas $[8,9]$.

No certain clinical and histological criteria are present to distinguish PC from APA. Therefore, differential diagnosis of such tumors from each other is difficult. While benign parathyroid diseases are seen more often in women, $\mathrm{PC}$ is seen equally in women and men [10]. In contrast to benign diseases, patients with PC generally present with severe hypercalcemia and serum ALP levels at higher levels [9]. While PTH levels can increase twelve times higher than normal levels in patients with PC, PTH levels are increased approximately two-fold higher than normal values in patients with PHPT [11]. Palpable neck mass is observed in $30-76 \%$ of patients with PC [12]. Even though our case was diagnosed with APA, serum Ca level was $17.2 \mathrm{mg} / \mathrm{dL}$, and iPTH level was increased thirteen times higher than normal ranges; however, ALP level was observed not to be so high in our case. On physical examination, a mass considered to be thyroid nodule was palpable on left thyroid lobe.

Neck US is the most commonly used method to localize parathyroid glands. Lobulated appearence and non-homogenous echogenity on US are often associated with PC [13]. Sestamibi scintigraphy is not specific for malignacy, but a useful method for displaying local and distant metastases [14]. Fine needle aspiration biopsy (FNAB) must be avoided because of tumor seeding and local relapse. The differential diagnosis between PC and APA is difficult, and surgeons should be alerted during operation due to the existence of large, firm and white-gray-colored tumor with infiltration of surrounding structures, suggesting PC [9].

On histopathological examination of PC, fibrous capsule, fibrous trabecules, trabecular or rosette-like cellular architecture, mitotic figures, capsular or vascular invasion are observed [15]. Ippolito et al indicated that the presence of vascular, capsular or tissue invasion and recurrence are the basic criteria for the diagnosis of malignacy and also reported that although often found in PC, broad fibrous bands, mitotic features, trabecular growth pattern and atypical nuclear features are not pathognomonic and can be seen in APA. Welldefined connective capsule was absent in approximately half of patients with APA in their study [16].

Genetic predisposition to PC is well-known, and hyperparathyroidism-jaw tumor syndrome is known to be a rare autosomal dominant inherited disorder and associated with PC. Hyperparathyroidism 2 tumor suppressor gene (HRPT2) is also considered to be responsible for the hyperparathyroidism-jaw tumor syndrome. HRPT2 encodes a protein called parafibromin, a tumor suppressor protein. Parafibromin is involved in the cell-cycle regulation by inhibiting cell proliferation and blocking cyclin-D1 expression [10]. 
The diagnostic value of several markers used for distinguishing between these tumors (Ki-67, p53, bcl-2, cyclinD1) is limited, because inconsistent differences are present between expressions of these markers on PC, APA and parathyroid adenoma [17]. The existence of local recurrence or metastatic disorder is the single and reliable characteristic in distinguishing between benign and malignant parathyroid disorders [18].

In our case, an appearence consistent with parathyroid adenoma on neck US was absent, and the mass palpable on physical examination was considered to be a thyroid nodule. Because the sestamibi scan suggested the existence of parathyroid adenoma, no FNAP was performed.

Surgery is the most effective treatment choice for PC, and so en bloc resection is preferred [9]. Along with ipsilateral thyroid lobectomy and removal of contiguous lymph nodes (tracheoesophegeal, paratracheal and upper mediastinal) from the ipsilateral central neck, parathyroidectomy should be performed during en bloc resection. Unfortunately, intraoperative frozen-section is ineffective in order to confirm diagnosis of cancer [9]. If carcinoma is suspected on laboratory investigation, and the findings intraoperatively reveal the existence of carcinoma, en bloc resection should be conducted at initial surgery because of the confirmation of PC following pathological evaluation [12, 19]. Patients for whom no en bloc resection was performed but diagnosed with PC via pathological examination should be re-assessed for surgery due to thyroidectomy, isthmectomy, paratracheal and central lymph node dissection. In our case, only parathyroidectomy was carried out, and no additional surgical intervention was considered as histopathological analysis was consistent with APA.

Despite the suggestive signs of $\mathrm{PC}$, such as the presence of high levels of $\mathrm{Ca}$ and $\mathrm{PTH}$, thick fibrous bands and parathyroid cell proliferation invading the capsule seen on histopathological examination, our case was diagnosed as APA because of low Ki-67 proliferation index, and the absence of mitosis, vessel invasion and adjacent tissue invasion. Suspicious histological features of such lesions increase the probability of being precancerous. However, further studies are needed to enlighten clinical course of APA.

\section{Conflicts of Interest}

Authors declare that there is no conflict of interest.

\section{References}

1. Koea JB, Shaw JH. Parathyroid cancer: biology and management. Surg Oncol. 1999;8(3):155-165.

2. Aldinger KA, Hickey RC, Ibanez ML, Samaan NA. Parathyroid carcinoma: a clinical study of seven cases of functioning and two cases of nonfunctioning parathyroid cancer. Cancer. 1982;49(2):388-397.

3. Levin KE, Galante M, Clark OH. Parathyroid carcinoma versus parathyroid adenoma in patients with profound hypercalcemia. Surgery. 1987;101(6):649-660.

4. Clayman GL, Gonzalez HE, El-Naggar A, Vassilopoulou-Sellin R. Parathyroid carcinoma: evaluation and interdisciplinary management. Cancer. 2004;100(5):900905.

5. McKeown PP, McGarity WC, Sewell CW. Carcinoma of the parathyroid gland: is it overdiagnosed? A report of three cases. Am J Surg. 1984;147(2):292-298.

6. Fraser WD. Hyperparathyroidism. Lancet. 2009;374(9684):145-158.

7. Lal G, Clark OH. Diagnosis of primary hyperparathyroidism and indications for parathyroidectomy. In: Clark OH, Duh QY, Kebebew E, editors. Textbook of Endocrine Surgery. Philadelphia: Elsevier; 2005. pp.384-392.

8. Fernandez-Ranvier GG, Khanafshar E, Jensen K, Zarnegar R, Lee J, Kebebew E, Duh QY, et al. Parathyroid carcinoma, atypical parathyroid adenoma, or parathyromatosis? Cancer. 2007;110(2):255-264.

9. Fang SH, Lal G. Parathyroid cancer. Endocr Pract. 2011;17(Suppl 1):36-43.

10. Digonnet A, Carlier A, Willemse E, Quiriny M, Dekeyser C, de Saint Aubain N, Lemort M, et al. Parathyroid carcinoma: a review with three illustrative cases. J Cancer. 2011;2:532-537.

11. Chen Q, Kaji H, Nomura R, Sowa H, Yamauchi M, Tsukamoto T, Yamaguchi T, et al. Trial to predict malignancy of affected parathyroid glands in primary hyperparathyroidism. Endocr J. 2003;50(5):527-534.

12. Shane E. Clinical review 122: Parathyroid carcinoma. J Clin Endocrinol Metab. 2001;86(2):485-493.

13. Hara H, Igarashi A, Yano Y, Yashiro T, Ueno E, Aiyoshi $\mathrm{Y}$, Ito $\mathrm{K}$, et al. Ultrasonographic features of parathyroid carcinoma. Endocr J. 2001;48(2):213-217.

14. Al-Sobhi S, Ashari LH, Ingemansson S. Detection of metastatic parathyroid carcinoma with Tc-99m sestamibi imaging. Clin Nucl Med. 1999;24(1):21-23.

15. Stojadinovic A, Hoos A, Nissan A, Dudas ME, Cordon-Cardo C, Shaha AR, Brennan MF, et al. Parathyroid neoplasms: clinical, histopathological, and tissue microarray-based molecular analysis. Hum Pathol. 2003;34(1):54-64.

16. Ippolito G, Palazzo FF, Sebag F, De Micco C, Henry JF. Intraoperative diagnosis and treatment of parathyroid cancer and atypical parathyroid adenoma. Br J Surg. 2007;94(5):566-570.

17. Bondeson L, Larsson C, Grimelius L, Arnold A, De Lellis RA, Eng C, et al. Parathyroid carcinoma. In Pathology and Genetics of Tumours of Endocrine Organs, De Lellis RA, Lloyd RV, Heitz PU, Eng C (eds). IARC 
Press: Lyons, 2004.pp.124-127.

18. Flye MW, Brennan MF. Surgical resection of metastatic parathyroid carcinoma. Ann Surg. 1981;193(4):425435.
19. Fujimoto Y, Obara T, Ito Y, Kanazawa K, Aiyoshi Y, Nobori M. Surgical treatment of ten cases of parathyroid carcinoma: importance of an initial en bloc tumor resection. World J Surg. 1984;8(3):392-400. 